\title{
Assessment of the impact of using Augmented Reality to support learning
}

\section{Eduardo Guzmán ${ }^{a}$}

${ }^{a}$ Escuela Politécnica Superior de Alcoy, Universitat Politècnica de València (UPV). Alcoy (España), e-mail: eguzman@cigip.upv.es

\begin{abstract}
Augmented Reality (AR) is changing the perception of education in the way of learning, therefore, in the way of teaching, consolidating AR as part of the future of education, but not only in this field, but in general in the medicine, industry, transportation, marketing, architecture, entertainment and tourism. Currently, education seeks new techniques that help and facilitate students to improve compression. The present work makes a study of the use of Augmented Reality for the improvement of learning, from an analysis of the technological development of this technology, the types of software on the market to create augmented models, and an analysis of the use of this technology in the education, then an application, for the Logistics course of the Master's Degree in Organisational and Logistics Engineering of the Universitat Politècnica de València, with this application we intend to innovate in traditional educational strategies. Once this tool was created, we evaluated the use of Augmented Reality with the students of the subject, in which users determined that AR facilitates the learning process and motivates their participation in the subject.
\end{abstract}

Keywords: Augmented reality, mobile learning, educational technology

\section{Introduction}

Actual education system assumes important challenge, such as the global pandemic of COVID-19, which has changed work, learning and entertainment environments, the World Economic Forum (Papagiannis, 2020) mentions the impact of Augmented Reality (AR) on society and how Educators have changed online learning models, highlighting that AR could help overcome isolations, by allowing access to cultural events and experiences through AR or virtual reality applications, an example of this are 185 first-year medical 
students at Case Western Reserve University (CWRU) are using HoloLens and HoloAnatomy, an award-winning AR app by Cleveland Clinic and CWRU, to learn from their own homes (Papagiannis, 2020).This and other applications help to understand human anatomy in $3 \mathrm{D}$, so the learning of these students would not be limited to just medical texts or spaces with corpses for dissection.

Papagiannis (2020) describes Augmented Reality as a tool that helps bring the outside world into a living room or bedroom, through visualization, since it allows an object to be taken or a concept to be understood in a way that would otherwise be it would be difficult to understand, imagine or make the invisible visible

Studies on augmented reality reveal the great potential of this technology, in fields such as medical education, it has not only been useful for the training of students through the creation of visual information on organs, bones, virtual reconstruction of parts of the body that are difficult to recognize and data of patients undergoing to operation, while at the same time helping patients to get involved and learn about procedures, medical techniques, and treatments ( Hanna et al., 2018; Campisi et al., 2020). In fields such as psychology, it is used to treat the disorder of different phobias or animal insects, such as cockroaches or spiders, it can also be used to treat fear of heights (Juan et al., 2005). In arts education, it allows to interact with paintings, images, artistic samples, allowing users to see graphic figurations or listen to audios directly from an animation that comes out of the painting or watch videos directly from the painting, currently, museums are using this type of applications (Hart, 2020). In the industry, is used to support the manufacturing systems support planning process, AR helps the user to model or validate a process or to superimpose 3D models and access to information to understand the assembly or manufacturing processes (Paelke, 2014).

Augmented Reality is a technology that has become an important focus of research in education, several studies describe as Augmented Reality are useful to increase motivation, promote collaboration, develop spatial skills and improve performance in physical tasks (Radu, 2014). AR is currently generated in mobile technologies such as phones or tablets, augmented reality becomes Mobile Augmented Reality (MAR) (López-Faican \& Jaen, 2020). Augmented reality allows real-world objects to complement each other with virtual elements so that these real and virtual objects coexist in the same space or real environment (Azuma et al., 2001). Commonly, the terms virtual reality and Augmented Reality are confused with each other due to their similarities. The difference between Virtual Reality and Augmented Reality is that AR modifies, improves or complements people's experience in a real environment, while virtual reality places it in a fully simulated environment or in an artificial world (Campisi et al., 2020). 
In this context, the present study evaluates the use of Mobile Augmented Reality and analyses the usability of this tool and the integration of classroom work with the augmented reality environment, in addition to investigating the effects of AR technology on university students.

\section{AR-LOG}

We have developed an application called "AR-LOG" (AUGMENTED REALITYLOGISTIC) this application allows students to complement and reinforce the knowledge taught in the Logistics subject. Students in this subject must learn concepts about warehousing, transportation of goods, and warehouse design. The objective of AR-LOG is to help understand the theoretical concepts presented in the subject, allowing them to experiment with elements found in real warehouses such as forklifts, pallets, types of shelving and containers (see Fig. 1.).

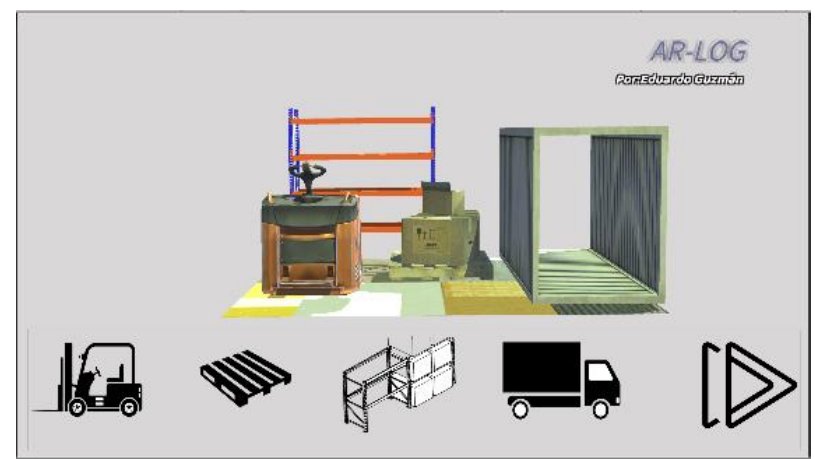

Fig. 1. Initial screen (AR-LOG).

Font: (Guzmán Ortiz, 2017)

\subsection{Technologies}

Software for the development of Augmented Reality has increased rapidly in recent years (Kljun et al., 2020), there are several tools that help bring the virtual world closer to the physical world, such as Google AR (https://arvr.google.com/ar/), this is a technology that allows to carry out from a classroom or living room a virtual safari, visit museums and make expeditions to mountains or historical monuments compatible with the SDK (Software Development Kits) ARCore (Android) and ARKit (iOS). Tools like Spatial (https://spatial.io/) allow to generate Augmented Reality content such as 3D avatars from a selfie. Increasingly mobile devices support apps created by Augmented Reality SDK, there 
are different SDKs on the market, such as ArtoolkitX (http://www.artoolkitx.org/); ARMedia (http://www.armedia.it/index.php); Aumentaty (http://www.aumentaty.com/community/en/) that presents a community to share educational content in AR; Vuforia (https://developer.vuforia.com/) this technology allows to recognize $3 \mathrm{D}$ images and objects.

\subsubsection{Software and Hardware}

AR-LOG application was written in $\mathrm{C} \#$ and the Unity tool was used, and within this software, we use the Vuforia (SDK) and the Application Programming Interface (API). The reason for choosing Vuforia is that it is compatible with iOS and Android, and therefore with most mobile devices, including phones and tablets. Vuforia also uses a tool that analyzes images and objects in 3D. The image recognition process is carried out through the edges, that is, it detects the corners, the tips of an edge of an image, in this way, the images represent Image Targets (see Fig. 2.). Vuforia detects and tracks Image Targets, causing their content to augment.

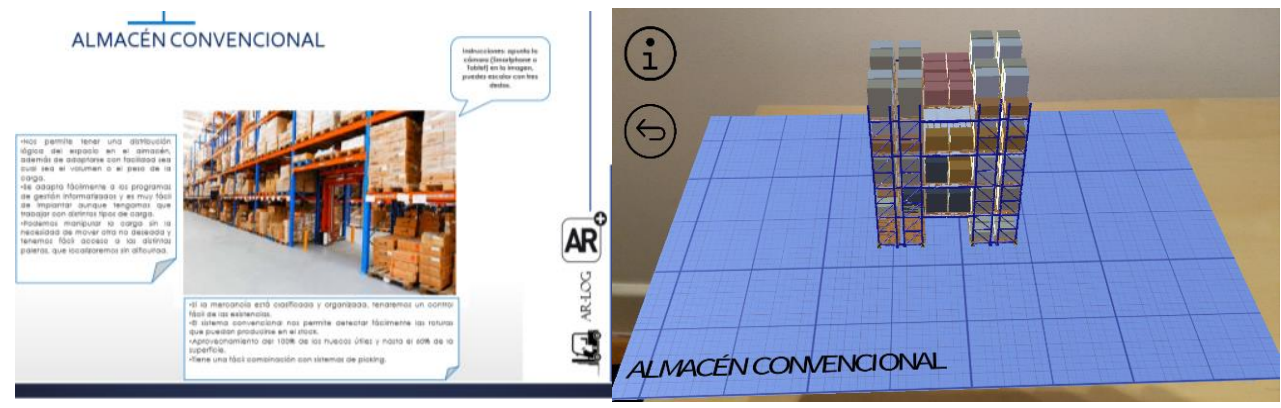

Fig. 2. Image Target and Augmented space.

Font: (Guzmán Ortiz, 2017)

The application was loaded on a smartphone (Samsung Galaxy S7 edge) and a tablet (Samsung Galaxy tab 2) for testing.

AR-LOG has an initial animation with some of the elements that can be seen in Augmented Reality (see Fig. 1.), to access the models, users must select and click on one of the buttons (icons), when press the button the user accesses the information and models in augmented reality, the buttons shown in Fig. 1 go from left to right and correspond to forklifts, pallets, different types of racks and containers, respectively. It also has a button at the end (right) in which the user when pressing will find all the elements studied in a single animation, these elements are located imitating the characteristics of a real warehouse.

The AR models are positioned and oriented on the basis of the size of an A4 sheet (see Fig. 2.) this sheet and the $3 \mathrm{D}$ models respect a scale of 1:14.4, this scale corresponds to real models (scale toys) that are used in the practical classes of the subject (see Fig. 3.). 


\subsection{The process of integrating AR-LOG into activities of the subject}

Students received 12 templates (Image Target) printed on A4 size sheets (see Fig. 3.) however the templates can be displayed on devices such as computers or tablets. The templates detail the main characteristics of the topics under study and also instruct how to use AR-LOG, these templates have a dual purpose, the first is that it provides information on the topic and the second is that students can take notes of elements they see AR models in addition to the professor's explanation.

At the beginning of the experiment, students do not receive any information about the operation of the application, to reduce the novel effect of AR, in addition, the templates inform how to control the model in augmented reality, students can change the size of AR models with their hands, rotate and move them, additionally when they access the AR model and press the information button (i) (see Fig. 2), this button takes them to a web page where you will find additional information on the subject under study.

When the students press a button, they enter a topic and they just have to change the template and immediately the augmented reality model changes and provides the information on the topic of the template (see Fig. 3.) until the moment the student decides to change the topic and must change templates.

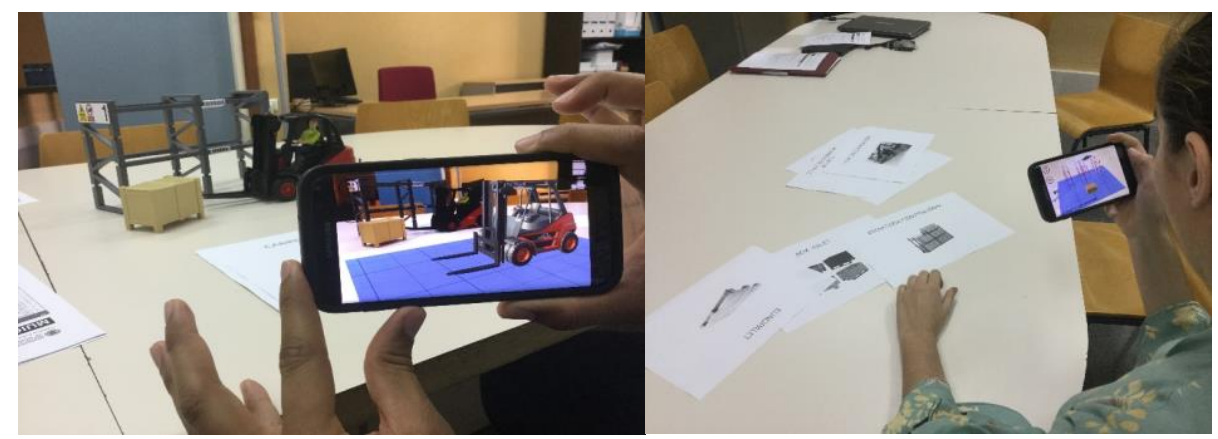

Fig. 3. Students are evaluating AR-LOG.

Font: (Guzmán Ortiz, 2017)

\section{Methodology}

\subsection{Participants}

The research took place at the Universitat Politècnica de València, a total of 15 students and 2 professors from the logistics course of the Master's Degree in Organisational and 
Logistics Engineering participated in the experiments. Participants voluntarily attended the experimental evaluation.

\subsection{Results}

To obtain the opinion of the students on the experience of the application, a questionnaire was applied. The applied questionnaire allows us to obtain quantitative and qualitative data related to the applicability of AR-LOG.

The questionnaire contains 18 closed and 1 open questions, the questions are valued from one to five, being; 1: strongly disagree; 2 : disagree; 3 : neither agree nor disagree; 4: agree; 5: totally agree.

The response of the users regarding the architecture or interface of the application is shown in Fig. 4. These questions seek to determine if the experience with AR-LOG is interactive in the teaching-learning process and at the same time if it is functional.

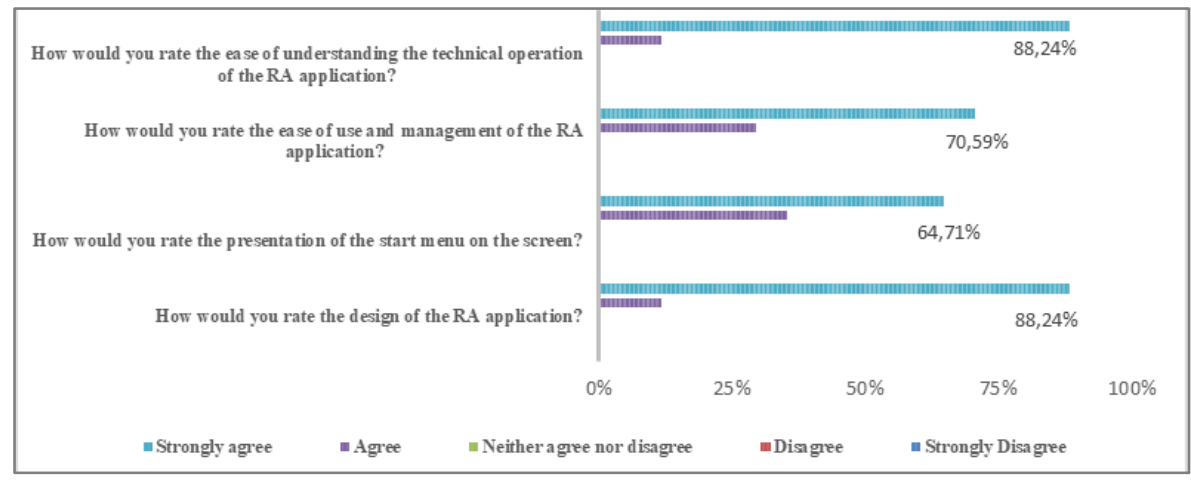

Fig. 4. Results questionnaire: architecture or interface.

In general, according to the results shown in Fig.4. the interface and the design of the application are attractive for users, in general, most of the students affirmed that the design is correct, as well as its ease of use, which would demonstrate that AR-LOG is useful, interactive and easy to use.

Also asked about 3D models, these questions identify if the presented models improve the learning process and if they are consistent with the knowledge acquired in the study of the logistics course, and to know if the use of these models will help to develop a vision of spatial knowledge. As a result of these questions, $100 \%$ of the respondents considered that the models are close to reality. They also confirmed that Augmented Reality is a tool that encourages learning and makes the teaching process effective, as $94.12 \%$ of respondents said that using the Augmented Reality application would help them remember the 
theoretical content seen in class, and also serves to solve theoretical doubts, since experiencing $3 \mathrm{D}$ and comparing with the real world allows for greater attention.

Other questions related to the usefulness of the application is to know if the students had fun using AR-LOG. $100 \%$ of the students said they totally agree that the application is fun and more than $70 \%$ said they totally agree that Augmented Reality aroused more interest in the topic and that it would help to keep the attention on the topics covered and more than $82 \%$ considered that the use of augmented reality in other subjects would improve and reinforce learning.

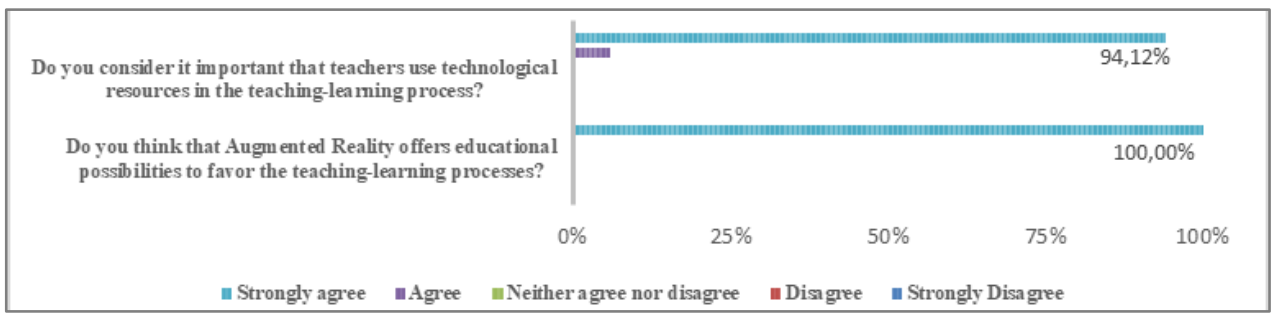

Fig. 5. Results questionnaire: teaching-learning processes.

Finally, we evaluated whether AR could facilitate the teaching-learning processes (see Fig. 5). The results confirm that the use of this type of technology would represent a positive change in the traditional educational system. There are many tools that help increase students' skills in the classroom (computers, software, multimedia materials, etc.). The educational system and teachers seek to increase student motivation. The student motivation increases the chances of completing a task compared to those who are not motivated (Di Serio et al., 2013). In consequence, AR benefits the teaching-learning processes, as demonstrated by $100 \%$ of the students (see Fig. 5.) and provides a positive impact on student motivation, which generates greater participation and effort in learning activities.

\section{Discussion}

The main objective of this work is to evaluate the use of Mobile AR and analyze the usability of this tool and the integration of work in the classroom with the augmented reality environment. In this context, it was identified that AR generates positive effects on students, generating greater motivation, which generates gains in the learning process, in fact, the use of technology is useful to support and improve learning. These findings were contrasted with the hypotheses of similar studies such as those presented by (Conley et al., 2020; Fidan \& Tuncel, 2019; López-Faican \& Jaen, 2020), these studies demonstrated the 
advantages of learning with RA and without RA, in which they conclude that this technology contributes to learning, attitude, motivation, attention and retention of students.

\section{Conclusions}

As education evolves and the global environment changes, the incorporation of new technologies such as Augmented Reality will replace traditional learning techniques. The use of tools such as the application presented has proven to be useful to improve learning and, therefore, advantageous in teaching processes, since it arouses interest in study subjects through AR models, what allows to understand the theoretical concepts effectively as well as the development of spatial vision, since it allows access to virtual elements in real-time through a two-dimensional image.

Augmented reality has many positive implications of widespread use, although the technology for this type of application is still expensive, many development tools are free. The use of Augmented Reality admits to being used by anyone, users without specific knowledge of programming or software can use this type of tool, even applications like the one presented can work without the Internet, they only need a smartphone or tablet and with a device operating system Android or iOS.

\section{Acknowledgments}

Funding by the Conselleria de Educación, Investigación, Cultura y Deporte - Generalitat Valenciana for hiring predoctoral research staff with Grant (ACIF/2018/170); European Social Fund with Grant Operational Program of FSE 2014-2020, the Valencian Community.

\section{References}

Azuma, R., Baillot, Y., Behringer, R., Feiner, S., Julier, S., \& MacIntyre, B. (2001). Recent Advances in Augmented Reality. IEEE Computer Graphics and Applications, Nov.-Dec, 34-47. https://doi.org/10.1109/38.963459

Campisi, C. A., Li, E. H., Jimenez, D. E., \& Milanaik, R. L. (2020). Augmented Reality in Medical Education and Training: From Physicians to Patients BT - Augmented Reality in Education: A New Technology for Teaching and Learning (V. Geroimenko (ed.); pp. 111-138). Springer International Publishing. https://doi.org/10.1007/978-3-030-42156-4_7

Conley, Q., Atkinson, R. K., Nguyen, F., \& Nelson, B. C. (2020). MantarayAR: Leveraging 
augmented reality to teach probability and sampling. Computers and Education, 153(April), 103895. https://doi.org/10.1016/j.compedu.2020.103895

Di Serio, Á., Ibáñez, M. B., \& Kloos, C. D. (2013). Impact of an augmented reality system on students' motivation for a visual art course. Computers and Education, 68, 586-596. https://doi.org/10.1016/j.compedu.2012.03.002

Fidan, M., \& Tuncel, M. (2019). Integrating augmented reality into problem based learning: The effects on learning achievement and attitude in physics education. Computers and Education, 142(September 2018), 103635. https://doi.org/10.1016/j.compedu.2019.103635

Guzmán Ortiz, B. E. (2017). Estudio de viabilidad del uso de la realidad aumentada para la mejora del aprendizaje. Desarrollo de un prototipo para la asignatura de Logística. [Universitat Politècnica de València]. https://riunet.upv.es:443/handle/10251/91210

Hanna, M. G., Ahmed, I., Nine, J., Prajapati, S., \& Pantanowitz, L. (2018). Augmented reality technology using microsoft hololens in anatomic pathology. Archives of Pathology and Laboratory Medicine, 142(5), 638-644. https://doi.org/10.5858/arpa.2017-0189-OA

Hart, C. (2020). The Romantic App: Augmented Reality in Fine Art Education. In V. Geroimenko (Ed.), Augmented Reality in Education: A New Technology for Teaching and Learning (pp. 279325). Springer International Publishing. https://doi.org/10.1007/978-3-030-42156-4_16

Juan, M. C., Alcaniz, M., Monserrat, C., Botella, C., Banos, R. M., \& Guerrero, B. (2005). Using augmented reality to treat phobias. IEEE Computer Graphics and Applications, 25(6), 31-37. https://doi.org/10.1109/MCG.2005.143.

Kljun, M., Geroimenko, V., \& Čopič Pucihar, K. (2020). Augmented Reality in Education: Current Status and Advancement of the Field. In V. Geroimenko (Ed.), Augmented Reality in Education: A New Technology for Teaching and Learning (pp. 3-21). Springer International Publishing. https://doi.org/10.1007/978-3-030-42156-4_1

López-Faican, L., \& Jaen, J. (2020). EmoFindAR: Evaluation of a mobile multiplayer augmented reality game for primary school children. Computers and Education, 149(April 2019). https://doi.org/10.1016/j.compedu.2020.103814

Paelke, V. (2014). Augmented reality in the smart factory: Supporting workers in an industry 4.0. environment. IEEE Emerging Technology and Factory Automation (ETFA), 1-4. https://doi.org/10.1109/ETFA.2014.7005252.

Papagiannis, H. (2020). 3 ways Augmented Reality can help us with COVID-19 and beyond. World Economic Forum. https://www.weforum.org/agenda/2020/04/augmented-reality-covid-19positive-use/

Radu, I. (2014). Augmented reality in education: A meta-review and cross-media analysis. Personal and Ubiquitous Computing, 18(6), 1533-1543. https://doi.org/10.1007/s00779-013-0747-y 